\title{
Hacking Body Politics: Tackling the Technical Tropes
}

\author{
Michelle Christensen \\ Technische Universität Berlin / \\ Berlin University of the Arts \\ michelle.christensen@tu-berlin.de
}

\author{
Florian Conradi \\ Technische Universität Berlin / \\ Berlin University of the Arts \\ florian.conradi@tu-berlin.de
}

\begin{abstract}
As the rationale and reason of the 'internet of things' progresses vigorously to encompass all things, organic and inorganic, animate and inanimate, conscious or not - including all aspects of our increasingly connected bodies, an 'internet of organisms' (loO) seems to be steadily transpiring. As socially fabricated organic subjects now turned artificially intelligent corporeal objects in the loO - in the surveillance of information capitalism, our bodies and actions are mined, and on this base, patterns are fabricated, predictions concocted, and suggestions devised. But as posthuman bodies, can we not conspire with systems and things as allied artifice to hack back the larger apparatuses of power that we are immersed in? Rather than acting as the janitors of the machinery - can we be malfunctioning code, a screw loose in the contraptions of power? Exemplified by works from a design inquiry, this article argues that we must evolve as fluid negotiated un/common bodies with things, being precise with obscurity, transforming metadata into 'betadata', and DIY re-cyphering our entangled embedded bodies.
\end{abstract}

Capitalized bodies. Posthuman (h)activism. Critical making. Practice-based design research.

\section{INTERNET OF ORGANISMS}

As the rationale and reason of the 'internet of things' progresses vigorously to encompass all things, organic and inorganic, animate and inanimate, conscious or not - including all aspects of our increasingly connected bodies, an 'internet of organisms' seems to be steadily transpiring. These are times where all boundaries have been ruptured between nature and culture, object and subject, and human and machine (Haraway 1985; 1994), where new dynamics have given birth to an extremely entangled posthuman contrivance tethered into an apparatus of 'smart' and 'intelligent' artifice. While our thoughts are engendered by neurons, technologically mediated social interactions and by our machines themselves, our bodies are repaired, transplanted and manufactured with prosthetic enhancements ranging from contact lenses and tattoos to robotic limbs and search engines (Hillis 2016). Socially fabricated organic subjects now turned artificially intelligent corporeal objects in the loO - the basic principles and concepts on which we have based the understanding of ourselves hitherto, at least since the darkness of the enlightenment and the flawed fantasies of humanism, seem to have fractured and cracked along the rims of reason (Braidotti 2013; 2017). And so, although we like to perceive ourselves as rationale, autonomous, sovereign subjects, as the wardens of our own trailblazing hard- and software inventions - we seem to find ourselves acting as the extensions of the extensions that we built.

As ubiquitous chips and sensors find their way into all the bits and pieces of everyday life, enabling the capturing of nanoscopic data at a geopbytic scale, the analogue workings of our busy bodies are accumulated and digitised. These are times when our steps and their exact locations leave footprints, and health trackers monitor our bodies in real-time as we go about our daily business. Where meticulously logged data from 'confidential' online searches and dating sites, as well as from fertility and cycle-tracking apps, sanction million-dollar profits of intimate data (Lupton 2014; 2016), and where we are oftentimes not entirely sure who exactly can access the innermost archive of our being. In times of big data, our bodies and actions are mined, and on this base, patterns are fabricated, predictions concocted, and suggestions devised.

In the surveillance of information capitalism, Rosi Braidotti argues, what the neo-liberal market forces are financially investing in, is the informational power of 'living matter' itself. This capitalization of living matter produces an entirely new political economy, introducing discursive and material political techniques of individual and population 
control of a very different order. And as we voluntarily register and record, upload and share, the predictive analytics of the human as data culminate in profiling practices that amount to what Braidotti describes as 'life mining' - with visibility, predictability and exportability as the key criteria. And so, as tracking extends to DNA testing and brain fingerprinting, neural imaging, body heat detection and iris recognition, new technologies are growingly occupying posthuman bodies as surveillance techniques applied in civil society (Braidotti 2013, 62), emerging a state of surveillance capitalism that claims human experience as free raw material (Zuboff 2019).

This is what Michel Foucault depicts in his terms of biopower and governmentality, namely the ways in which power manifests itself in the mundanity of daily practices and routines. As individuals engage in self-surveillance and self-discipline, subjugating themselves unwittily to a whole complex of apparatuses, they are transmitting and putting in motion relations that are not relations of sovereignty, but those of domination (Foucault 1977, 195). And so, as things are increasingly knowing, telling, advising and aligning amongst themselves, consolidating with corporeality - power is dispersed throughout bodies and societies, becoming inherent in social relationships and embedded in networks of practices, operating simultaneously on the multiple micro-levels of everyday life. Operating within and on our very bodies, as material-discursive norms and normalities are produced and maintained. And these are not modes of domination that present themselves as a single identifiable antagonist that has to be defeated, but as an entire system of interests, restrains, assumptions, conscious and unconscious fears - and together, all these forces constitute a ceaselessly shifting apparatus, which no-body commands or owns.

Within these uncompromising dimensions of lifemining as a mode of governmentality, where bodies are discernibly and allusively connected, shadowed, trailed, classified and governed, an increasingly transparent human emerges. We steadily transpire as inverse cyborgs, as the extension of our extensions, being furtively followed and carefully conducted, being governed by each other and by ourselves. And as we continue to colonize new spaces - from our environments to our bodies, with interconnected and always on technologies, we are steadily removing the haptic interface, as we proceed to become the interface itself. As Zygmunt Bauman puts it - just as snails carry their homes, so the employees of the brave new liquid modernity must grow and carry their personal panopticons on their own bodies' (Bauman and Lyon 2013, 53).
And so, standing in the shade of our own data shadows, the transparent human sprints to generate footprints like never before, meanwhile smartwatches race to count heartbeats, and social forums track our browser behaviour even when we are not logged in, as well as our whereabouts even when we turn off the location settings on our devices (Gibbs 2017). As our own social constructions hastily trip and stumble in an attempt to keep up with the material world, the individual struggles to comprehend the systems that they materialize in - and just eat less, run more, unwind and breathe. Surrendering to the suggestive state of affairs based on an aggregate of algorithmic assumptions - 'if you like this, you might also like that' - we begin to start acting as surrogates of ourselves.

Nevertheless, although power is an omnipresent dimension in human relations, Foucault argues, power in society is never a fixed and closed regime. Rather, it is an endless and open strategic game. At the very heart of the power relationship, and existing as an unremitting provocation to it, he argues, are the recalcitrance of the will and the intransigence of freedom (Foucault in Gordon et al. $1991,5)$. How then, can we take this ability of nonacceptance, and apply it to renegotiate our increasingly detrimental relationships to (and as) things? As posthuman bodies, how can we align as artifice to hack back the larger apparatuses of power that we are immersed in? Rather than acting as the janitors of the machinery - can we be malfunctioning code, a screw loose in the contraptions of power?

\section{ALGORITHMIC ASSEMBLAGES}

Within the context of a practice-based design research project, critical approaches from design and sociology were merged to concoct a series of experiments in which human and nonhuman aligned to protest against the complex systems of power in which they are commonly embedded. Using the means of critical practice, live sociology and autoethnographic recording, a form of immersive research was performed, in which the researcher acts in a dual position of being both researcher and researched - as well as transpiring to be both the designer and the work itself. The project was an endeavour into merging corporeally with systems in order to form a common alliance, exploring alternative conceptions of 'body-data'. By fabricating a networked cloak and a series of scannable tattoos, a 'second skin' of the human was prototyped in order to open up possibility spaces of both human and nonhuman, exploring the idea of becoming together - forming an embodied treaty with things. 


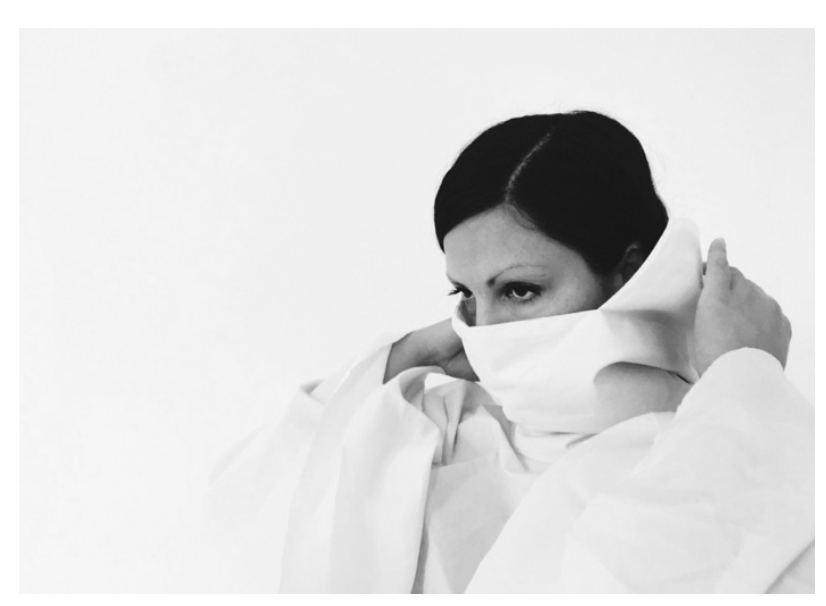

Figure 1: Cloak - a device for phantom action

In the first stage of the experiment, an 'invisible' cloak was developed as a passive device for active use - a device for phantom action. As our phones are most often the middlemen between us and our a/social digital selves, acting as friend and helper as much as spy and conniver - this work attempted to interfere with the network of oneself, one's phone and the online network that all parties are connected into. Inside the cloak were over forty hidden NFC tags (near field communication tags), each tasked with performing an action when coming in contact with one's phone - performing a specific search based on antithetical interests to the ones of the wearer. When elusively roaming around therefore, the covert tags respond to one's indirect fidgety gestures with the phone, releasing the actions upon coincidental encounters, triggering searches that were targeted at blurring any sense of a clear or stabile social profile of the wearer. Occupying the networks that it engages in with non-intentional interests, the cloak hides its wearer in commonalities, blurring any chance of producing a clear self. By using the most basic parameters of what bots, crawlers and surveyors are looking for, what one is interested in and searching for, the cloak uses the tags to incessantly activate sporadic tasks, as one arbitrarily hovers over it.

In this way, the cloak provided a shield of sorts, as it practiced its own social (h)activism by just hanging on and around you. It needed its artificial and human counterparts to act, as an allied form of protest. The human in this scenario provides the element of random programming through its movements - as it aligns with the mechanical you, and thereby with your haphazard moving around and carrying out unforeseen physical gestures. The phone on the other hand becomes the intermediary, as it mediates between fleetingly powering the NFC tags when hovering over them and doing the deed of searching. The collaboration of coincidental human-nonhuman action fabricates a serendipitous rendering of a social profile, as the un-rehearsed social-material

performance produces an accidental account.

Thereby, while we are ceaselessly being read, reasoned and re-produced, the precipitateness of the cloak attempts to leave breadcrumbs for whoor whatever is crawling and depicting. It wants to be found, be read and be known. In this sense, rather than hiding in the dark, believing that there would be dungeon deep enough to be out of reach, the cloak employs the tactic of hiding in the light. It expresses a maxim of 'overdone as undercover', messing with the patterns that you become by making metadata 'betadata'. It plays ping-back with the networks that it is infused into, making it more difficult for the information to be categorised, and making its own subtle suggestions in a society of delicate influence and subdued seduction, as a ploy of fighting soft power with soft power. Instead of going into the body, one might say, this was an experiment into going out of it, defusing the body in a social blur.

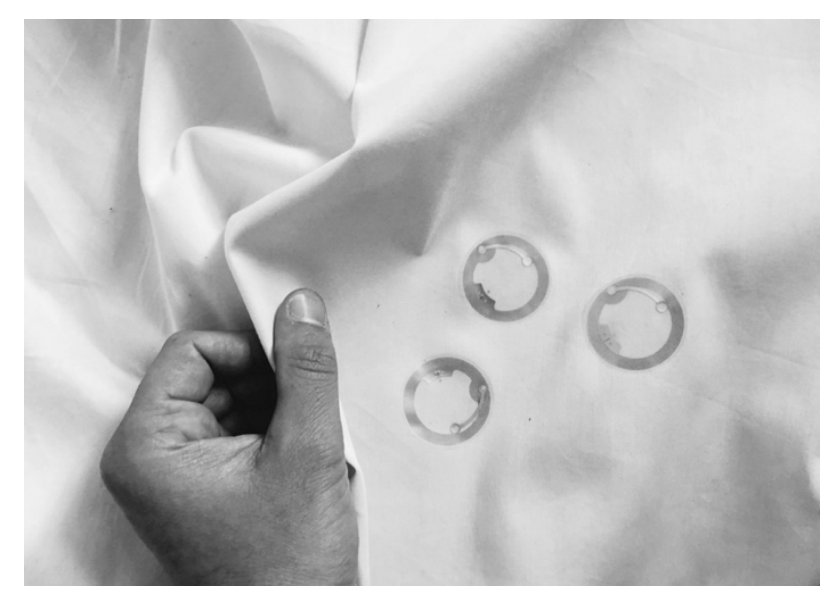

Figure 2: NFC tags used inside the cloak

And so, through being seen for the sake of obscurity, the human in this algorithmic assemblage emerges as a cooperative system with the nonhuman to become a slightly distorted projection of themselves - a social hologram of sorts, and perhaps a blind-spot in the apparatus of the translucent human. If we carry around our own personal panopticon on our bodies as the snail carries its home, yielding to the powers as we promptly upload our innermost selves in the uttermost delivery of data, then the cloak forms a in/visible cover that absorbs the panoptic power. It provokes a misreading in its attempt to confuse the systems reading it, and hence in order to make the categorisation and reproduction composed by them more difficult. Thus, over time it also challenges the wearer, making their own reproduction more strenuous, as they enter into a mode of diligent confusion. In this way, the effect of the random engagements not only serve to disrupt the process 
of being read, but also that of the wearers reading. This, as it alters what might be suggested to such a phantom obscured social profile, and as an actively fractured subject - 'whom' might be found.

In a sense therefore, besides acting as a social shield, the mantle provides an add-on social - a parallel functioning to both enact and corrupt the watcher and the watched. It constructs a countercontext, a re-contextualising of oneself in a society of monitoring, recommendations and submissions. In a strive to locate escape routes and tactics, the cloak attempts to infuse the values of irregularity and disorder into the everyday life of its wearer. Because in the Internet of Everything and Everyone, we can never stand outside of the system, but perhaps we can embrace it by becoming it, in order to hide in it. As a concerted indiscipline, where we enter willingly into confusion, we can align to produce a material politics with things - joining forces with the material and the network to emerge into becoming the construct itself. Working at the periphery of reason, and flirting with indirect power, we can take the social noise - and make it louder. As shared bodies of resistance, through post-anthropocentric unions, we can engage into in(di)visible partnerships.

In the following stage of the experiment the 'second skin' took on the form of carrying temporary tattoos, which contain hidden codes that when scanned with a phone trigger an action. In times where we are informed, notified, advised and instructed from all sides, we rarely have the opportunity to position ourselves on ourselves.

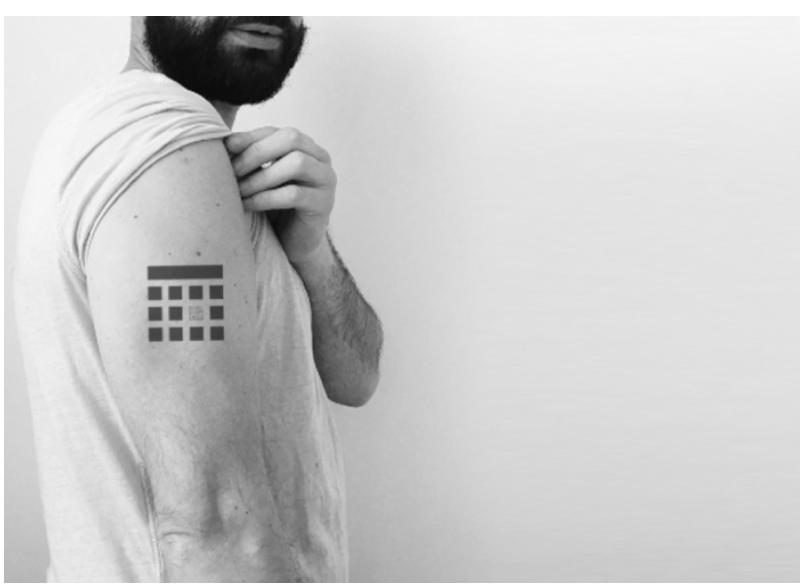

Figure 3: Example temporary tattoo with scannable code

Therefore, for instance, hidden behind the 'Flo-bot' code is a rather low-tech programmed version of Florian, a superego of sorts, which could respond to all of his questions, albeit in a rather hazy way (much like the analogue guy). By scanning himself a message appeared, and thus Florian could engage into extensive conversations with the Flobot about could-haves, would-haves and shouldhaves.
In another example, Michelle became part of the cloud. In times of massive storage and ceaselessly progressing personal big data, where the clutter sometimes seems to weigh us down physically as we cannot keep up with our own repositories, this was an attempt of creating a space of digital denial. On the cloud she could simply drop all the files that were unnecessarily occupying her mind - those messages, documents, expectations and requests which merely mess up one's space with guilt and bad conscience, as her 'body' stored the items for her. When scanning the code, she was linked to an overview of how much of the space was full, and how much still free. In this way, much like measuring one's blood pressure or heartbeat, she could measure her dark space, and if she liked, erase it all.

Sometimes, these indivisible analogue-digital unions included both us and our surrogate selves. As a live and embodied chat-bot, the sometimes rather socially awkward conversations between Florian and the Flo-bot emerged as a mediation with himself - and with his own body. In an overloaded interconnected social lifeworld, this action allowed for the access to one's gut feelings and quivering subconscious emotions, which sometimes seem to get lost in an action-reaction society. As power is increasingly being materialised in quantitative measurements of factual aspects such as heartbeats, sleep cycles, steps taken and calorie intakes - this was an experiment into moving from quantified to qualified data. One could argue that as we usually deal with our quantified selves, we are anyway engaged deeply in a process of interpretation - as the parameters for aspects such as 'sleeping enough', 'eating too much' or 'being too stressed' are clearly interpretive - or at least highly generalised. Thereby, dealing with the quantified self is anyhow, or should most definitely be, a process which must be treated as entering into an interpretive conversation with oneself. In this way, the aspect of speaking with ones alter-ego was really not that removed from current tendencies at all. Nevertheless, the difference in this experiment was the engagement into a negotiation with the post-mechanical body rather than basing the dialogue on medical or measurable content, it meant entering into an engagement with interpretive reading. For this reason, the reactions from the Flo-bot are based on acutely generalised wording - taking language known from chat acronyms and text message shorthands, it responded with open answers such as 'NTIM' (not that it matters), 'IRL!' (in real life!), 'EM?' (excuse me?) or 'OTL' (out to lunch). In this way, and as one knows it from instant-messaging with anyone, bot or not, one can only read the limited content through personal associations, interpretations and feelings. And so, as a mirror image, it reflects back. In this sense, while the 
experiment bordered on a play with the superstitious super-ego, it nevertheless left animism behind - the Flo-bot is nothing else than a clearly fuzzy reflection - a diplomatic instance between an over-mediated environment and an over-mediated guy.

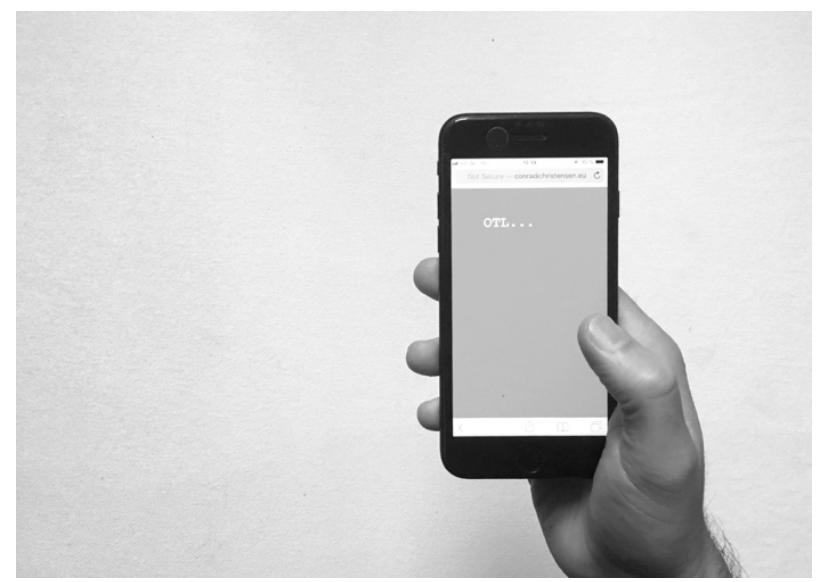

Figure 4: Example 'Flo-bot' response

The aspect of partaking in the dialogues that took place somewhat in a slightly parallel dimension, continued to present itself in several of the other works carried out in the study in different ways. The feature can be found in the aspect of 'becoming cloud', for instance, in the adding of a phantom extension to one's body in the form of a 'dark space', in which one can collect and store one's ceaselessly emerging digital denial. In this case, the phantom dialogue lay in the engagement with having the option to drop something in the strange space, carrying it around on one's own body and making it one's own, making the digital suppression a tangible option in the swarming powers of everyday life. It enabled the engaging oneself in an indirect conversation between oneself and one's other self, as one of us perhaps became slightly brighter as the other became increasingly dimmer. Similarly, the cross-dimensional conversation also transpired in the cloak, with which we united to speak in tongues, both displaying an engagement somewhere between fact and fiction, and the entering willingly into a blurry parallel phantom actuality. In a sense, the cloak initiated and carried out its own conversations, perhaps with a series of bots and crawlers of which we will never know, as well as with the unfolding network itself.

Acknowledging the importance of decentralizing the human in times of these transpiring parallel powers, not least in times where the borderlines of what is real or fake, significant or trivial, under our command or entirely beyond it become difficult to draw, this project attempted to enter into a phantom social dialogue with our fellow systems and things. It did this in the third and a half dimension - not quite aiming for a fourth dimension of social spacetime but adding some definite relativity. Thereby, it attempted to form curious bodily extensions for counter context, to fracture reproductions, re-enchant disenchantment, and as the power was shared between multiple parties - to achieve a slightly higher degree of ungovernmentality. As subjectivities in these experiments trembled, quivered and fluttered to become hazy and obscure, we engaged into the un-mining of overpopulated bodies, creating data that was odd enough to counter precarious predictions and social forecasting. In this way, the works carried out within this study attempted to construct micro-meshworks of people, systems and things. As entangled political-connected posthuman bodies, where most often the its outnumber the mes' (Bennett 2010,113), it was an endeavour into emerging into the system of becoming to see what one might become. It was an attempt to actively fracture and splinter one's own selfhood and subjectivity, deliberately sharing autonomy with 'the others'. This as a hyperactive-activism, rather than reproducing a pre-determined or pre-meditated account. It meant acting out together, although not always consistently or in agreement, as an open generative labyrinth of systems.

\section{TACTICAL BODIES}

In her book 'The Nick of Time - Politics, Evolution, and the Untimely', Elizabeth Grosz argues that we must come to understand the body not as an entity in itself, but rather as a system - or even a series of open-ended systems that are functioning within other vast systems that it cannot control - and it is through this that it can access and acquire its abilities and capacities (Grosz 2004, 3). And so, if our bodies are opened up anyway, functioning as open-ended systems operating within open-ended systems - do we not want to engage into becoming an insurgent part of that becoming? Before we merely emerge to be the extensions of the state, the industry or of our own egos - do we not want to be part of deflating the power dynamics before we all lose any sense of sway? Are we not willing to enter into a treaty with systems and things decentralizing the self as a severe decentralization of power, in order to emerge as DIY open-source self-coded material-discursive bodies?

This would provide the potential, perhaps, to move from being the human-prosthetic of things, to becoming nothing more than a force - casting spells to re-enchant the entanglement. Battling the strong and their strategies with tactics, with the power of the dispersed - as Michel De Certeau's rebellious and tactical dweller, who poaches and tricks, using polymorphic situations (Certeau 1984, 37). Or what Geert Lovink and David Garcia expanded to what they term 'tactical media' - using 
the value of a temporary reversals in the flow of power to be never perfect, always in becoming and involved in a continual process of questioning the premises of the channels one works with (Garcia and Lovink 1997). This would mean transpiring to become dwellers as and in open-ended systems who engage in the battle between commons and capitalism as rehearsing and performing bodies, that negotiate wills and hierarchies to include more critical and sharable multiplicities.

As a practice, this would entail a merging of Certeau's tactics with the approach of critical making. Because critical making uses democratic technologies - free and open source software and hardware - to connect materiality with the politics of its affects, attempting to consolidate critical thinking with critical fabrication (Ratto 2011). And tactical making, as a synthesis, means being technically troublesome, making clutter in the categories, using tactics to fool with technics - it means fighting algorithmic authoritarianism with DIY, lost-and-found and low-tech tactics. It is a mode of putting things (and oneself) into a divergent context, in order to explore what they could be, opening up technologies before we too quickly assume and accept what they are.

The very rough ad-hoc 'body-hacks' carried out in this project reflect an attempt to prototype reshifting and blurring the powers operating around one's posthuman body - expanding what a body can mean, what body data could do, and how one in a negotiation with one's nonhuman counterparts can emerge as a counterapparatus. As a mode of occupying the body, now flesh and network, to free it for a moment - in a reconsideration of how it should be decided upon and governed. In this sense, within the counterapparatus, the 'apparatus' must be perceived not merely as a counter action to 'outside' forces - the being governed by, but furthermore as a resistance toward the self, and its self-governing. The self in this scenario must moreover not be perceived as an independent or autonomous human self, but as one that is caught up in an entangled becoming with many 'others' (Haraway 2006:3), operating in an intertwined process of using and being used, informing and being informed, acting and being enacted.

The works emerging from these experiments delineate an example of what it could begin to mean that we act as open so(u)rcerers, practicing a mode of illusion, a subtle waggish wizardry, to reenchant ourselves rather than continuing to operate as technocratic extensions in a state of cultural robotics. Being social shamans in order to take back the body from operating as a techno-organic prosthetic of the multiple connected devices and apparatuses - being faulty nodes in the network, critical malware in our own social programming. Despite the algorithmic assumptions of information capitalism, which so unremittingly transpose their suggestive seductions, the human must remain an inconclusive body of work, an unfinished object indecisively in(con)vincible.

As data adds an unprecedented level to bio-power, and governmentality becomes the tumultuous art of the governed no longer being able to perceive when they are being governed, we must evolve as fluid negotiated un/common bodies with things, being precise with obscurity, transforming metadata into 'betadata', and DIY re-cyphering our entangled embedded bodies.

\section{REFERENCES}

Bauman, Z. and Lyon, D. (2013) Liquid Surveillance: A Conversation. Cambridge, UK: Polity Press.

Bennett, J. (2010) Vibrant Matter: A Political Ecology of Things. Durham, NC: Duke University Press.

Braidotti, R. (2017) 'Becoming-World Together: On the Crisis of Human' in Hello, Robot. Design between Human and Machine. Weil am Rein: Vitra Design Museum.

Braidotti, R. (2013) The Posthuman. Polity Press, Cambridge.

Braidotti, R. (2006) Posthuman, All Too Human Towards a New Process Ontology. Theory, Culture \& Society, Vol 23 (7-8), pp. 197-208.

Certeau, M. de (1984) The Practice of Everyday Life. Berkeley, CA: University of California Press.

Foucault, M. (1977) The Confession of the Flesh, in Gordon, C. (eds.) Power/Knowledge: Selected Interviews \& Other Writings 1972-1977. Pantheon Books, New York.

Garcia, D. and Lovink, G. (1997) The ABC of Tactical Media, Manifesto.

Gibbs, S. (2017) Google has been tracking Android users even with location services turned off, 22.11.2017, www.theguardian.com (accessed 04.12.2017)

Gordon, C., Burchell, G. and Miller, P. (eds.) (1991). The Foucault Effect: Studies in Governmentality. Chicago: The University of Chicago Press.

Grosz, E. (2004) The Nick of Time: Politics, Evolution, and the Untimely. Durham, London: Duke University Press.

Haraway, D. (1985) 'A manifesto for cyborgs: Science, technology, and socialist feminism in the 1980s'. Socialist Review, 5 (2), pp. 65-107. 
Haraway, D. (1994) A Game of Cat's Cradle: Science Studies, Feminist Theory, Cultural Studies, Configurations.

Haraway, D. (2006) When we have never been human, what is to be done? Theory, Culture \& Society, Vol. 23 (7-8), pp. 135-58.

Hillis, D. (2016) 'The Enlightenment is Dead, Long Live the Entanglement', Journal of Design and Science, MIT Press.

Lupton, D. (2014) Quantified sex: a critical analysis of sexual and reproductive self-tracking using apps. Culture, Health \& Sexuality, Vol. 17 (4), pp. $440-453$.

Ratto, M. (2011) 'Critical Making' in van Abel, B., Evers, L., Klaassen, R., Troxler, P. (eds.) Open Design Now: Why Design Cannot Remain Exclusive. Amsterdam: BIS Publishers.

Zuboff, S. (2019) The Age of Surveillance Capitalism. The Fight for a Human Future at the New Frontier of Power. New York: Public Affairs. 